\title{
A note comparing the welfare of Zebu cattle following three stunning-slaughter methods
}

\author{
J.E.G. Neves ${ }^{\text {a }}$, M.J.R. Paranhos da Costa ${ }^{\text {b,* }}$, R.O. Roça ${ }^{\text {c }}$, L. Faucitano ${ }^{\text {d }}$, N.G. Gregory ${ }^{\text {e }}$ \\ a Instituto Federal de Educação, Ciência e Tecnologia de Brasília - IFB, Campus Planaltina, 73.380-900 Planaltina, DF, Brazil \\ b Grupo ETCO, Departamento de Zootecnia, Faculdade de Ciências Agrárias e Veterinárias, UNESP, 14.884-900, Jaboticabal, SP, Brazil \\ c Departamento de Economia, Sociologia e Tecnologia, Faculdade de Ciências Agronômicas de Botucatu, UNESP, 18.610-307, Botucatu, SP, Brazil \\ d Agriculture and Agri-Food Canada, 2000 College Street, J1M 0C8 Sherbrooke, Quebec, Canada \\ e Royal Veterinary College, University of London, London, United Kingdom
}

\section{A R T I C L E I N F O}

\section{Article history:}

Received 4 December 2015

Received in revised form 3 February 2016

Accepted 22 February 2016

Available online 24 February 2016

\section{Keywords:}

cranial nerve reflexes

pain responses

penetrating captive bolt

non-penetrating captive bolt

shechita

\begin{abstract}
A B S T R A C T
The objective of this study was to assess welfare of cattle during bleeding after slaughter with or without stunning. A total of 434 bulls were distributed across three slaughter treatments: penetrating captive bolt stunning followed by chest sticking ( $\mathrm{PCB}, \mathrm{N}=279$ ), non-penetrating captive bolt stunning followed by halal slaughter ( $\mathrm{NPCB}, \mathrm{N}=67$ ) and shechita without previous stunning ( $\mathrm{SHE}, \mathrm{N}=88$ ). Four measures of possible consciousness and return to sensibility were recorded 20 and $60 \mathrm{~s}$ after bleeding as welfare indicators. They were the frequencies of responses to nostril stimulation and tongue pinch, spontaneous eye blinking, and rhythmic breathing. All responses were absent in stunned cattle at both 20 and 60 s, and in SHE cattle 7, 4, 10, and 100\% of the animals presented these responses, respectively. Repeat shots were required for $46 \%$ NPCB and $2 \%$ PCB $(\mathrm{P}<0.05)$. The application of religious slaughter without previous stunning may result in greater risk of cattle suffering, pain and distress at slaughter.
\end{abstract}

(c) 2016 Elsevier Ltd. All rights reserved.

\section{Introduction}

There are concerns in some sectors of society about the welfare of cattle during religious slaughter without stunning (Adams \& Sheridan, 2008). Several alternative approaches have been proposed to address these concerns. They include irreversible stunning applied before the neck cut (penetrating captive bolt stunning), irreversible stunning applied immediately after the neck cut, reversible stunning applied before the neck cut (non-penetrating captive bolt stunning), and modifying the neck cut reducing the risk of prolonged consciousness after the cut (Gregory et al., 2012; Mellor, Gibson, \& Johnson, 2009; Velarde et al., 2010). However, to our knowledge, the efficiency of these alternative stunning methods in terms of animal welfare is not well studied in comparison with religious slaughter.

The objective of this study was thus to assess the welfare of cattle, using as indicators the frequencies of brainstem responsiveness and physical responses to potentially painful stimuli during the bleeding period, after non-penetrating and penetrating captive bolt stunning applied before the neck cut, both compared with a religious slaughter method without stunning (shechita).

* Corresponding author.

E-mail addresses: julia.neves@ifb.edu.br (J.E.G. Neves), mpcosta@fcav.unesp.br (M.J.R. Paranhos da Costa), robertoroca@fca.unesp.br (R.O. Roça), luigi.faucitano@agr.gc.ca (L. Faucitano), neville@fcav.unesp.br (N.G. Gregory).

\section{Materials and methods}

This study was carried out according to the Brazilian legislation for humane slaughter, and the slaughtering procedures were done under the supervision of the Federal Veterinary Service, from the Brazilian Ministry of Agriculture, Livestock and Supply. The project was not evaluated by the Committee of Ethical Use of Animals because the data collection was performed before the publication of the Brazilian law number 11.794 of October 2008, defining the procedures for scientific use of animals.

\subsection{Animals and slaughter treatments}

This experiment was conducted at two abattoirs located in São Paulo State (Brazil), where three stunning-slaughter methods, namely penetrating captive bolt followed by chest sticking ( $\mathrm{PCB}$ ), non-penetrating captive bolt (NPCB) followed by a halal neck cut and slaughter without stunning by shechita (SHE), are usually performed. A total of 434 zebu (pure and crossbred) cattle were distributed across the treatments, in terms of 279 bulls for PCB, 67 for NPCB and 88 for SHE. The average carcass weight of cattle under study was $281.1( \pm 36.9) \mathrm{kg}$. For PCB and NPCB the cattle were restrained in an upright position in a stunning pen using a yoke and chin-lift, while for SHE cattle the shackle-andhoist method was used, as described by Grandin (2006). Each animal was forced to leap into the stun box, and dragged out after wrapping a 
chain in its back leg; then, they were cast onto their sides on the floor, tied with leg-ropes and the neck was stretched using a handheld chin extender which exerted pressure through a prong positioned the symphysis of the lower jaw.

Penetrating and non-penetrating captive bolt guns (Jarvis Products Corporation ${ }^{\circledR}$ ) were powered pneumatically with 180 to 190 psi and 160 to 170 psi (as required by the local halal authority), respectively. The diameter of the penetrating bolt was $15.9 \mathrm{~mm}$, while the head of the non-penetrating bolt was $34.9 \mathrm{~mm}$ wide.

\subsection{Assessment of shooting accuracy}

The number of animals in PCB and NPCB treatments which received more than one shot was recorded.

Shot accuracy was assessed by placing a transparent plastic grid, which showed the ideal shooting position onto the head of the shot animal and measuring the distance between the shot hole and the ideal shooting position. The ideal shooting position was defined as the cross-over point between imaginary lines drawn between the base of each horn and the corner of the eye on the opposite side of the head (Gregory, 1998).

\subsection{Assessment of cattle welfare}

To evaluate the state of consciousness and pain in cattle during bleeding several physical signs were assessed at 20 and $60 \mathrm{sec}$. following neck cutting in each of the three treatments. They were: palpebral reflex, corneal reflex, spontaneous blinking, rhythmic breathing (assessed at the muzzle and/or flank), and jaw muscle tension (in response to manually opening the mouth); and as pain responses to scraping a finger nail along the inner nostril, and response to pinching the tongue between a finger and thumb nail. In addition, the presence of righting reflex, defined as lateral turning of the head associated with apparent struggling movements, was noted when it occurred during the first $60 \mathrm{sec}$. of the bleeding period.

The intensity of physical convulsions was assessed at 20 and $60 \mathrm{sec}$. after neck cutting according to a four point subjective score, where score 0 corresponded to no convulsions, 1 to mild spasms with no leg paddling, 2 to moderate convulsions with leg paddling, but not sufficient to present a safety hazard for staff, and 3 to severe convulsions, including intense leg paddling activity, that may jeopardize staff safety.

\subsection{Statistical analysis}

Data were analysed by the Fisher exact test with Graphpad software (2015 GraphPad Software, Inc.) to compare the effects of the treatments on physical reflexes and responses of zebu cattle after stunning and slaughter. The individual animal was the experimental unit.

\section{Results}

\subsection{Shooting accuracy}

Repeated shooting was more frequently observed for NPCB than for PCB cattle ( 46 vs. $2 \%, P<0.001$ ). Because of the high frequency of repeated shooting with the non-penetrating gun, shot accuracy was only assessed in NPCB cattle. Most NPCB cattle (67\%) were shot in the wrong position, with $52 \%$ being shot within $2 \mathrm{~cm}$ of the ideal shooting position and $15 \%$ at more than $4 \mathrm{~cm}$ from the ideal position.

\subsection{Signs of consciousness}

Except for the proportion of cattle showing spontaneous blinking and response to tongue pinching at $60 \mathrm{sec}$. after bleeding, the slaughter procedure had an effect on the other signs of cranial nerve and brainstem responses. A greater $(P<0.05)$ proportion of cattle showed signs of brain function in the SHE treatment than in PCB and NPCB (Table 1). In particular, at $20 \mathrm{~s}$ following the neck cut the SHE cattle showed a higher frequency of responses to nostril stimulation, tongue pinch and spontaneous blinking compared to the PCB cattle and they also showed a higher frequency of responses to nostril stimulation and spontaneous blinking compared to the NPCB cattle, these being signs which are consistent with consciousness.

Most cattle did not show convulsions (score 0) at any time after being bled in any stunning-slaughter treatment. However, the degree of convulsions (score 1 to 3 ) at $20 \mathrm{sec}$. after slaughter was greater $(P<0.05)$ in PCB and NPCB than in SHE cattle, but at $60 \mathrm{sec}$. after the bleeding cut the proportion of SHE cattle showing convulsions was greater $(P<0.05)$ than that of PCB and NPCB cattle (Table 1$)$. The lower degree of convulsions early post-slaughter in SHE cattle may be explained by the restraining technique used during bleeding that may have limited the leg movements.

\section{Discussion}

To our knowledge, this is one of the few studies which applied potentially painful stimuli, such as pinching the tongue with finger and thumb nails and scraping the inner lining of a nostril with a finger nail, when assessing the effectiveness of religious slaughter methods in terms of cattle welfare.

Quoting Rosen (2004) "shechita is a painless and effective method by which to stun and dispatch an animal in one rapid act". Nevertheless, our results indicate that the potential for experiencing pain can be present after the cut since $7 \%$ of the cattle subjected to SHE in this study still presented at least one pain reflex at $20 \mathrm{sec}$. following the neck cut. In addition, all cattle subjected to SHE in this study still presented at least one cranial nerve reflex at $20 \mathrm{sec}$. following the neck cut and $93 \%$ had one or more positive reflexes or responses for at least $60 \mathrm{sec}$. These findings are in general agreement with the conclusions reported in previous studies (Bourguet, Deiss, Tannugi, \& Terlouw, 2011; Gibson et al., 2009; Gregory, Fielding, von Wenzlawowicz, \& von Holleben, 2010). However, these proportions are even greater than those reported by Bourguet et al. (2011), who assessed the efficiency of Halal slaughter without stunning and reported $57.5,47.2$ and $13.3 \%$ of the animals showing a

\section{Table 1}

Effect of three stunning-slaughter methods, penetrating captive bolt followed by chest sticking (PCB), non-penetrating captive bolt followed by a halal neck cut (NPCB), and slaughter without stunning by shechita (SHE), on the percentage of (434 zebu) cattle showing physical reflexes and responses.

\begin{tabular}{lccc}
\hline Stunning-slaughter methods (N) & PCB (279) & NPCB (67) & SHE (88) \\
\hline Variables (\% of occurrences) & & & \\
At 20 seconds after neck cutting & & & \\
+ ve palpebral reflex & $0^{\mathrm{a}}$ & $0^{\mathrm{a}}$ & $100^{\mathrm{b}}$ \\
+ ve corneal reflex & $0^{\mathrm{a}}$ & $0^{\mathrm{a}}$ & $98^{\mathrm{b}}$ \\
spontaneous blinking & $0^{\mathrm{a}}$ & $0^{\mathrm{a}}$ & $10^{\mathrm{b}}$ \\
rhythmic breathing & $0^{\mathrm{a}}$ & $0^{\mathrm{a}}$ & $100^{\mathrm{b}}$ \\
responding to nostril stimulation & $0^{\mathrm{a}}$ & $0^{\mathrm{a}}$ & $7^{\mathrm{b}}$ \\
responding to tongue pinch & $0^{\mathrm{a}}$ & $0^{\mathrm{ab}}$ & $4^{\mathrm{b}}$ \\
tense jaw muscles & $<1^{\mathrm{a}}$ & $1^{\mathrm{a}}$ & $83^{\mathrm{b}}$ \\
convulsion score 0 & $60^{\mathrm{a}}$ & $58^{\mathrm{a}}$ & $92^{\mathrm{b}}$ \\
convulsion score 1 & $27^{\mathrm{a}}$ & $27^{\mathrm{a}}$ & $8^{\mathrm{b}}$ \\
convulsion score 2 or 3 & $13^{\mathrm{a}}$ & $15^{\mathrm{a}}$ & $0^{\mathrm{b}}$ \\
At 60 seconds after neck cutting & & & \\
+ ve palpebral reflex & $0^{\mathrm{a}}$ & $0^{\mathrm{a}}$ & $93^{\mathrm{b}}$ \\
+ ve corneal reflex & $0^{\mathrm{a}}$ & $0^{\mathrm{a}}$ & $60^{\mathrm{b}}$ \\
spontaneous blinking & $0^{\mathrm{a}}$ & $0^{\mathrm{a}}$ & $2^{\mathrm{a}}$ \\
rhythmic breathing & $0^{\mathrm{a}}$ & $0^{\mathrm{a}}$ & $77^{\mathrm{b}}$ \\
responding to nostril stimulation & $0^{\mathrm{a}}$ & $0^{\mathrm{ab}}$ & $3^{\mathrm{b}}$ \\
responding to tongue pinch & $0^{\mathrm{a}}$ & $0^{\mathrm{a}}$ & $1^{\mathrm{a}}$ \\
tense jaw muscles & $<1^{\mathrm{a}}$ & $1^{\mathrm{a}}$ & $13^{\mathrm{b}}$ \\
convulsion score 0 & $83^{\mathrm{a}}$ & $100^{\mathrm{b}}$ & $80^{\mathrm{a}}$ \\
convulsion score 1 & $15^{\mathrm{a}}$ & $0^{\mathrm{b}}$ & $13^{\mathrm{a}}$ \\
convulsion score 2 or 3 & $2^{\mathrm{a}}$ & $0^{\mathrm{a}}$ & $7^{\mathrm{b}}$ \\
\hline
\end{tabular}

Means in a row without a common superscript letter were different at least at $\mathrm{P}<0.05$ 
corneal reflex at 10 and $30 \mathrm{sec}$ after the bleeding cut, and $30 \mathrm{sec}$ after animal suspension, respectively, and 16.3 and $12.8 \%$ showing palpebral reflex at 10 and $30 \mathrm{sec}$ after the bleeding cut, respectively. The different restraining techniques at the time of slaughter may explain the different proportion of animals showing signs of consciousness after bleeding between the two studies. In this study shechita animals were bled-out on the floor, which may have influenced the efficiency of the cut and the bleeding, while in the Bourguet et al. (2011) study animals were restrained in a rotary box equipped with body and head restraint, facilitating an easier cut. This technique is recommended by some authorities to facilitate neck cutting and improve bleeding (Grandin, 1992; Grandin \& Regenstein, 1994).

In contrast to SHE, most cattle subjected to PCB or NPCB stunning presented a deep level of concussion as shown by the loss of physical reflexes and responses which are dependent on the cranial nerves (Bourguet et al., 2011; Gregory, Lee, \& Widdicombe, 2007). However, the frequency of repeated shooting when the non-penetrating gun was used was unexpectedly high (46\%). The non-penetrating gun used in this study is the most common type of equipment in abattoirs which export halal beef in Brazil. It is compatible with the requirements of the local halal authorities, but was powered by a lower airline pressure compared with the penetrating gun, which may explain the greater need for a repeated shooting to ensure animal insensibility at bleeding.

\section{Conclusions}

Based on the results of this study, the application of religious slaughter without previous stunning may result in a greater risk of cattle suffering at slaughter. The use of better designed restraining devices for shechita slaughter may help improve its effectiveness. Further research and development work is also needed on a larger sample of animals for assessing the adequate airline pressure for the non-penetrating captive bolt gun to ensure a sufficient depth of concussion and prevent animal suffering during bleeding.

\section{Acknowledgements}

This study was part of the master thesis of the first author, presented for the Graduate Program in Animal Science at São Paulo State
University (UNESP), Faculty of Agricultural and Veterinary Sciences, Jaboticabal-SP, Brazil. During the master course she was sponsored by CAPES (Coordination for the Improvement of Higher Education Personnel).

\section{References}

Adams, D. B., \& Sheridan, A. D. (2008). Specifying the risks to animal welfare with livestock slaughter without induced sensibility. Paper prepared as a contribution for the Animal Welfare Branch, Product Integrity Animal and Plant Division, Australian Government Department of Agriculture, Fisheries and Forestry for the Animal Welfare Working Group of the Animal Health Committee, Primary Industries Standing Committee of Australia (Retrieved from: http://www.australiananimalwelfare.com.au/app/ webroot/files/upload/files/animal-welfare-livestock-slaughter.pdf, November 10th, 2014).

Bourguet, C., Deiss, V., Tannugi, C. C., \& Terlouw, E. M. C. (2011). Behavioural and physiological reactions of cattle in a commercial abattoir: Relationships with organisational aspects of the abattoir and animal characteristics. Meat Science, 88, 158-168.

Gibson, T. J., Johnson, C. B., Murrell, J. C., Hulls, C. M., Mitchinson, S. L., Stafford, K. J., ... Mellor, D. J. (2009). Electroencephalographic responses of halothane-anaesthetised calves to slaughter by ventral-neck incision without prior stunning. New Zealand Veterinary Journal, $57,77-83$

Grandin, T. (1992). Observations of cattle restraint devices for stunning and slaughtering. Animal Welfare, 1, 85-90.

Grandin, T. (2006, May 5). Improving religious slaughter practices in the U.S. Anthropology of Food (Retrieved from: http://aof.revues.org/93, February 3rd, 2016).

Grandin, T., \& Regenstein, J. M. (1994). Religious slaughter and animal welfare: a discussion for meat scientists. Meat Focus International, 3, 115-123 (Retrieved from: http:// www.grandin.com/ritual/kosher.slaugh.html, April 20th, 2015).

Gregory, N. G. (1998). Stunning and slaughter. In N. G. Gregory (Ed.), Animal Welfare and Meat Science (pp. 223-240). Wallingford, UK: CAB Publishing.

Gregory, N. G., Fielding, H. R., von Wenzlawowicz, M., \& von Holleben, K. (2010). Time to collapse following slaughter without stunning in cattle. Meat Science, 85, 66-69.

Gregory, N. G., Lee, C. J., \& Widdicombe, J. P. (2007). Depth of concussion in cattle shot by penetrating captive bolt. Meat Science, 77, 499-503.

Gregory, N. G., von Wenzlawowicz, M., von Holleben, K., Fielding, H. R., Gibson, T. J., Mirabito, L., \& Kolesar, R. (2012). Complications during shechita and halal slaughter without stunning in cattle. Animal Welfare, 21(Suppl. 2), 81-86.

Mellor, D. J., Gibson, T. J., \& Johnson, C. B. (2009). A re-evaluation of the need to stun calves prior to slaughter by ventral-neck incision: An introductory review. New Zealand Veterinary Journal, 57, 74-76.

Rosen, S. D. (2004). Physiological insights into Shechita. Veterinary Record, 154, 759-765.

Velarde, A., Rodriguez, P., Fuentes, C., Llonch, P., von Holleben, K., von Wenzlawowicz, M., ... Dalmau, A. (2010). Improving animal welfare during religious slaughter: Recommendations for good practice. Cardiff: Cardiff University, School of City and Regional Planning (Retrieved from: http://www.dialrel.eu/images/recom-light.pdf, April 26th, 2015) 